\title{
Leishmaniasis: Drug resistance and natural products (Review)
}

\author{
TILMAN POLONIO ${ }^{1}$ and THOMAS EFFERTH ${ }^{2}$ \\ ${ }^{1}$ Institute of Pharmacy and Molecular Biotechnology, University of Heidelberg, Heidelberg \\ ${ }^{2}$ Pharmaceutical Biology (C015), German Cancer Research Center, Heidelberg, Germany
}

Received March 31, 2008; Accepted May 12, 2008

DOI: $10.3892 /$ ijmm_00000020

\begin{abstract}
Epidemics of fatal visceral leishmaniasis caused by the intracellular protozoan Leishmania are a severe public health problem in tropical and subtropical regions of the world. One major drawback in the treatment of leishmaniasis is the emergence of resistance to current chemotherapeutics. Leishmanicidals have to be administered in low doses since commonly used drugs exhibit severe side effects, and hence drug resistance can appear rapidly. Since, to date, vaccination approaches have failed to enter clinical trials, chemotherapy based on small molecules is temporarily the exclusive treatment strategy. There is an urgent need for adding novel drugs with improved features to the pool of current chemotherapeutics. Many compounds derived from natural sources have pharmacological activities and may, thus, be of potential utility in drug development and biomedical research. Natural products, primarily plant-derived substances of diverse structural classes, have been described in the literature showing anti-leishmanial properties. In this review we provide a brief overview of the current treatment and the active principles of established drugs. Furthermore, we focus on the mechanisms of drug resistance and natural products that are promising leads for the development of novel chemotherapeutics.
\end{abstract}

\section{Contents}

1. Introduction

2. Disease and clinical manifestations

3. Standard chemotherapeutics, their mode of action and development of resistance

4. Screening of natural products

5. Conclusion

Correspondence to: Dr Thomas Efferth, Pharmaceutical Biology (C015), German Cancer Research Center, Im Neuenheimer Feld 280, D-69120 Heidelberg, Germany

E-mail: t.efferth@dkfz.de

Key words: anti-viral agents, chemotherapy, drug resistance, leishmaniasis, natural products, pharmacognosy

\section{Introduction}

The rapid emergence of drug resistance by the treatment of parasites with common chemotherapeutics requires the development of new drugs for future therapy. Novel drugs showing reduced toxicity will contribute to overcoming drug resistance and will improve current treatment. Besides rational drug design, natural product research shows promise in finding new lead structures. For example, in traditional Chinese medicine, the potential of plant extracts for the treatment of infectious diseases was recognized more than 2000 years ago. Today several compounds derived from plants or medical plants are applied in standard therapies, e.g. paclitaxel and Vinca alkaloids in cancer treatment or artemisinin as a potent anti-malarial drug. Plants are valuable sources for the screening of bioactive secondary metabolites, but also bacteria, fungi and terrestrial or marine invertebrates produce pharmaceutically useful compounds. Active compounds can be discovered successfully using modern biological screening assays. Subsequent derivatization of lead structures can improve the therapeutic profile of known substances. For validation of in vitro results, in vivo studies are essential and will also dictate whether a compound enters clinical trials. In this review, small molecules derived from natural sources will be presented that are promising agents against Leishmania parasites. Current treatment of infections caused by Leishmania relies solely on chemotherapy, and, to date, vaccine development has not been successful. However, advanced studies with various vaccine preparations have been conducted (recommended vaccination srategies are reviewed in refs. 1-3). This review will outline general facts concerning leishmaniasis and the associated pathogen. Clinical aspects and the current treatment strategies will be presented as well as drug resistance mechanisms. Finally, selected natural products will be highlighted which are important lead compounds for novel drug development.

\section{Disease and clinical manifestations}

Leishmaniasis is a prevalent disease in many parts of the tropical and subtropical world, causing significant morbidity or mortality. The disease is a severe public health problem in many developing countries of East Africa, the Indian subcontinent and Latin America. According to the World Health Organization (WHO), the pathogen is endemic in 88 countries and the magnitude of the disease is estimated to be 12 million infected people with 350 million people at risk. The rate of 
new cases per annum is estimated to be 2 million (1.5 million cases of cutaneous and 0.5 million cases of visceral Leishmaniasis) worldwide (4). Depending on approximately 20 different Leishmania species and subspecies, leishmaniasis exhibits a broad spectrum of clinical manifestations. Cutaneous leishmaniasis (CL) causes skin ulcers, which result in marked disfigurement if multiple lesions accumulate. More than $90 \%$ of CL cases occur in Afghanistan, Algeria, Pakistan, Iran, Saudi Arabia, Syria, Brazil and Peru (5). Though, not all Leishmania species remain localized in the infection site as in CL. Dissemination of certain species leads to systemic infections as in visceral leishmaniasis (VL), also called kala-azar. VL causes infections of the liver, spleen and bone marrow and is fatal if left untreated. Ninety percent of VL cases occur in India, Sudan, Bangladesh, Nepal and Brazil (5). In mucocutaneous leishmaniasis (MCL) the parasite escapes to the mucosal membranes, namely the mouth, nose and throat cavities. Infections produce destructive and mutilating skin lesions (6). MCL cases frequently occur on the Latin America subcontinent and are seldom found elsewhere. Furthermore, there is an increasing incidence of opportunistic co-infections among HIV/AIDS-infected patients living in areas where Leishmania is endemic (7). Leishmaniasis is caused by the obligate intracellular parasite Leishmania spp. Like Trypanosoma, Leishmania belongs to the kinetoplastid family. The parasitic protozoa are transmitted by female sand flies belonging to the genus Phlebotomus or Lutzomyia. The parasite enters the sand flies by sucking the blood of infected humans or terrestrial mammals. The life cycle of Leishmania spp. is divided between distinguishable forms in the sand fly and in human or animal hosts. In the midgut of the vector, the parasite exists as an extracellular, flagellated promastigote and develops into an infectious metacyclic promastigote. During a subsequent bloodmeal the parasite is inoculated into the skin of the host. The parasites are internalized by macrophages, dendritic cells or neutrophils, loosing their flagella while transforming into amastigotes. The amastigotes are able to persist in phagolysosomes and replicate through binary fission $(8,9)$. Infected phagocytotic cells then burst and release amastigotes, which further infect either additional tissue macrophages or disseminate throughout the reticulo-endothelial system, depending on the species. CL is primarily caused by L. major and L.tropica in the old world and L. braziliensis and L. mexicana in the new world (6). L. braziliensis is also the principal causative agent for MCL, though additional species have been described (L. amazonensis, L. panamensis and L. guyanensis) (10). VL is caused by L. donovani in the Indian subcontinent, Asia and East Africa or L. infantum in Europe, North Africa and Latin America. The pathogenic species and the immunocompetence of the host govern the clinical outcome of the disease. In CL, localized skin lesions are often self-healing if the immune response is able to eliminate the infection leading consequently to the generation of lifelong resistance to re-infection (11). Chronic progress of the disease occurs when the immune responses fail, which is substantially due to impaired T helper cell type 1 (Th1) responses and reduced macrophage activation (12). Migration of the parasites throughout the reticulo-endothelial system leads to VL which is systemic and non-healing. Not only are $L$. donovani and $L$. infantum able to visceralize, but species that normally cause self-healing lesions can also cause visceralizing infections. As in the case of VL, MCL is also non-healing if untreated and often appears years after infection.

\section{Standard chemotherapeutics, their mode of action and development of resistance}

For six decades, pentavalent antimonials $\left(\mathrm{Sb}^{\mathrm{V}}\right)$ have been the first-line drug in the treatment for all types of leishmaniasis. Two organic salt preparations, sodium stibogluconate $\left(\right.$ Pentostam $^{\circledR}$ ) and meglumine antimoniate (Glucantime ${ }^{\circledR}$ ) are principally used. Antimonials are administered intravenously or intra-muscular, and side effects like chemical pancreatitis, elevations in serum aminotransferases and electro-cardiographic abnormalities are usually reversible (9). One major drawback of therapy is the drastic emergence of resistance against antimonials. A prominent example is Bihar State in India, where the cure rate of antimony therapy against VL declined to merely $35 \%$, making conventional treatment no longer useful (13). Recent data suggest a rather complex mode of action of antimonials, acting on multiple target sites. The route of entry to the intracellular parasite remains unclear, however, there is strong evidence that pentavalent antimony acts as a pro-drug and must be reduced into the trivalent form to exhibit biological activity. Aquaporine-1 transporters in the plasma membrane of amastigotes are able to transport trivalent metalloids into the cell (14), though reduction into the trivalent form occurs only in a minor amount in phagolysosomes of the macrophage. The major amount is possibly converted within the parasite (15). Two important proteins have been described recently, which are able to mediate the reduction into trivalent antimony: LmACR1, an arsen-specific reductase (16) and TDR1, a thiol-dependent reductase using glutathione as a reductant (17). Non-enzymatic reduction is probably mediated by the reducing agents glutathione and trypanothione, the latter is unique in kinetoplastida $(18,19)$. Trivalent antimony is a potent inhibitor of parasite-specific trypanothione reductase (20). Inhibition of the trypanothione reductase causes oxidative stress which is due to decreasing amounts of reducing equivalents ( $\left.\mathrm{T}[\mathrm{SH}]_{2}\right)$. Resistance to antimonials in laboratory mutants are based on overexpression of the rate-limiting enzymes for thiol-biosynthesis, ornithine decarboxylase (ODC) and $\gamma$-glutamylcysteine synthetase $(\gamma$-GCS $)$, respectively (20). However, there are contrary observations in field isolates $(21,22)$. Complex formation of trivalent antimony with thiols has been reported in both laboratory mutants and field isolates. Metal complexes are sequestered by the ABC-transporter MRPA into intracellular vesicles (23), though their role in resistance is thought to be minor. Furthermore, it has been suggested that a related transporter is present in the plasma membrane of the parasite, which directly pumps metal-thiol complexes out of the cell. It has recently been shown that infection of macrophages with L. donovani induces up-regulation of P-glycoprotein (P-gp, MDR1) and multidrug resistance-related protein 1 (MRP1) expression in the host cells resulting in non-accumulation of antimonials in infected macrophages (24). Amphotericin B is the second-line drug in the therapy of VL. This polyene antibiotic originally derived from Streptomyces nodosus is 
predominantly used as a systemic antifungal agent. Two preparations are currently used for treatment: amphotericin B desoxycholate (Fungizone ${ }^{\circledR}$ ) and liposomal formulations (e.g. AmBisome $\left.^{\circledR}\right)$ (25). High cure rates are obtained in treatment of antimonial-unresponsive patients, though severe side effects such as renal toxicity and high costs limit the general use of amphotericin B in therapy. The liposomal formulation increases efficacy due to a drug-targeting effect and reduces toxicity. The mechanism of action is based on the high affinity of amphotericin B to ergosterol, the prevalent sterol in the plasma membrane of the parasite. It is thought that amphotericin B forms aqueous pores within the plasma membrane $(26,27)$. As a result, permeability to monovalent cations and small metabolites increases. Several resistant laboratory mutants have been produced by increasing drug pressure with altered lipid compositions in the plasma membrane. Ergosterol is replaced by different precursor sterols lacking C-24 methylation $(28,29)$. It has been reported that impaired biosynthesis is due to an absent splice-leader sequence in the C-24 methyltranserfase transcript (30). To date, no clinical resistance to amphotericin B has been found in Leishmania. No marked resistance has emerged in the field which is probably due to the reduced capability for infection of amphotericin Bresistant strains. Miltefosine (hexadecylphosphocholine), the first oral drug used in treatment, has been introduced recently, and advanced clinical trails are currently in progress (31). Miltefosine is registered in India, Germany and Columbia (Impavido ${ }^{\circledR}$ ). Originally developed as an antitumor drug, miltefosine is promising particularly in VL treatment (32). However, it has been shown that miltefosine is teratogenic in animal models, and drug resistance can easily be established in the laboratory (33). Miltefosine is translocated across the plasma membrane by the miltefosine transporter LdMT (P-type aminophospholipid translocase) (34). Furthermore, translocation depends on its putative $\beta$-subunit LdRos3, belonging to the CDC50/Lem3 family (35). Miltefosine mediates apoptotic-like cell death in L. donovani (36), and, moreover, inhibition of alkyl-specific-acyl-CoA acyltransferase has been reported (37). However, the actual mechanism of action is unknown. Drug resistance is easily established in the laboratory in multiple ways. First, single point mutations in the miltefosine transporter LdMT cause decreased or defective inward-directed translocation $(38,39)$. Two overexpressed ABC-transporters were identified in experimental drugresistant $L$. tropica strains. ABC-transporters are responsible for increased drug efflux, leading to reduced drug accumulation. Miltefosine is an allocrit for the ABCB1-transporter LtrMDR1 (38) and the ABCG-like half-transporter LiABCG4 (40). According to these findings, it is likely that resistance will rapidly emerge in the field, particularly when miltefosine is used as a single agent against VL. Pentamidine (e.g. Pentam ${ }^{\circledR}$ ), a diamidine, has been used in the treatment of antimonialresistant VL. However, the response rate decreased below $78 \%$ during a short time range of usage, indicating rapid development of drug resistance (41). Pentamidine is currently not utilized in the treatment of VL in India and infrequently used for CL. The mode of action of pentamidine has not been fully elucidated. It has been suggested that pentamidine binds to the DNA minor groove and inhibits topoisomerase II (42). Furthermore, it has been reported that pentamidine affects polyamine biosynthesis (43) and causes complex II inhibition in the respiratorial chain (44). Drug resistance in amastigotes is mediated by PRP1, an intracellular ABC-transporter (ABCC7) (45). There are several other potential drugs in various stages of clinical development. Paromomycin, an aminoglycoside antibiotic derived from Streptomyces rimosus, is currently being used as a topical formulation in CL and has passed phase III trials for VL. In bacteria, aminoglycosides inhibit protein synthesis by binding to ribosomes. It has been reported that ribosomes are also a target for paromomycin in Leishmania (46). Moreover, it has been suggested that paromomycin generates alterations in membrane composition and fluidity (47) and affects mitochondria (48). Drug-resistant strains have been generated in the laboratory (49), though resistance has not been observed in the field to date, since paromomycin has not been used extensively. Allopurinol, a xanthine oxidase inhibitor has been used infrequently for more than 20 years in combination with antimonials or pentamidine $(50,51)$. Sitamaquine, an 8-aminoquinolone, reached clinical trials for oral treatment of VL $(52,53)$. The mode of action is not well understood. However, there is evidence that sitamaquine is rapidly metabolized in more polar compounds, which may play an important role in anti-leishmanial activity. Drug uptake, the mechanism of action and potential drug resistance have not yet been rigorously demonstrated. Finally, several antifungal azoles, ketoconazole, itraconazole and fluconazole have undergone clinical trials for CL and VL $(54,55)$. Azoles are potent inhibitors of $14-\alpha$-demethylase, an enzyme involved in sterol metabolism responsible for ergosterol biosynthesis, though it has been reported that the parasite is able to survive with an altered sterol composition, induced by treatment with certain azoles (56).

\section{Screening of natural products}

Besides rational drug design and high throughput screening of compound libraries, screening of natural products is a valuable approach to discover new leads. In this section, we provide an outline of promising anti-leishmanial drug candidates derived from natural sources. Since a huge body of literature has been published on this subject, this review will focus on the most promising compounds from natural sources, selected by their pharmacological activity against promastigotes and amastigotes, cytotoxicity and the availability of in vivo studies. This list will include compounds which have been previously reviewed elsewhere. In addition, novel compounds described between 2006 and 2007 were added in order to update previously published lists of leishmanicidals (reviewed in refs. 57-60).

Flavonoids. Luteolin [1] and quercetin [2] isolated from Vitex negundo (Verbenaceae) and Fagopyrum esculentum (Polygonaceae) are potent anti-leishmanial compounds with $\mathrm{IC}_{50}$ values against $L$. donovani intracellular amastigotes of 12.5 and $45.5 \mu \mathrm{M}$, respectively (Fig. 1). Both compounds are able to induce topoisomerase II-mediated kinetoplastid DNA minicircle cleavage in $L$. donovani promastigotes and intracellular amastigotes. Treatment of promastigotes with luteolin and quercetin leads to cell cycle arrest in the G0/G1 phase followed by apoptotic cell death. In vivo studies have shown 
<smiles>C=CC(C)(C)c1cc(/C=C/C(=O)c2ccc(O)cc2)c(OC)cc1O</smiles>

(1)<smiles>COc1cc(O)c(C(=O)/C=C/c2ccccc2)c(O)c1</smiles>

(4)<smiles>C/C=C/c1ccc2ccccc2n1</smiles>

(7)
(2)<smiles>C=CC1CC2=C(CC(=O)OC2)OC1OC1OC2O[C@@H]1[C@H](OC(=O)c1c(O)cc(O)cc1-c1cccc(O)c1)C(O)C2O</smiles>

(5)

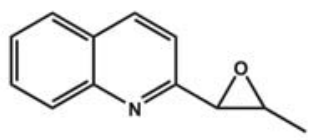

(8)
(3)<smiles>CC1=CC(=O)c2c(O)cccc2C1=O</smiles>

(6)<smiles>CCCc1ccc2ccccc2n1</smiles>

(9)

Figure 1. Chemical structures of anti-leishmanial compounds. Luteolin [1], quercetin [2], licochalcone A [3], 2',6'-dihydroxy-4'-methoxychalcone [4], amarogentin [5], plumbagin [6], chimanine B [7], chimanine D [8] and 2-n-propylquinoline [9].

that luteolin reduced the splenic parasite load of infected rodents by $80 \%(3.5 \mathrm{mg} / \mathrm{kg}$ body weight) and quercetin by $90 \%$ (14 $\mathrm{mg} / \mathrm{kg}$ body weight). Luteolin appears to be nontoxic to normal human T-cells, though quercetin induced cell cycle arrest (61). It has also been reported that luteolin and quercetin are specific inhibitors of topoisomerase I, which is an unusual bi-subunit topoisomerase in Leishmania (62).

Chalcones. Licochalcone A [3], an oxygenated chalcone isolated from Chinese liquorice Glycyrrhiza spp. (Fabaceae), exhibits strong anti-leishmanial activity, markedly preventing the growth of L. major and L. donovani promastigotes and amastigotes (63) (Fig. 1). $\mathrm{IC}_{50}$ value of licochalcone A against L. donovani intracellular amastigote was $0.9 \mu \mathrm{g} / \mathrm{ml}(2.7 \mu \mathrm{M})$ and $7.2 \mu \mathrm{g} / \mathrm{ml}(21 \mu \mathrm{M})$ against L. major promastigotes (64). In vivo studies with hamsters have shown that the parasite load in the spleen and liver was reduced up to $96 \%(20 \mathrm{mg} /$ $\mathrm{kg}$ body weight x 6 days) (65). Other oxygenated chalcones exhibited comparable potency (64). No cytotoxic effects have been observed in human leucocytes, lymphocytes and monocytes. Licochalcone A and related chalcones are able to destroy the mitochondrial ultrastructure. Furthermore, the compounds are strong inhibitors of fumarate reductase in L. major (66). 2',6'-Dihydroxy-4'-methoxychalcone (DMC)
[4] isolated from Piper aduncum (Piperaceae) showed activity against L. amazonensis promastigotes and intracellular amastigotes (Fig. 1). $\mathrm{ED}_{50}$ values were $0.5 \mu \mathrm{g} / \mathrm{ml}(1.9 \mu \mathrm{M})$ and $24 \mu \mathrm{g} / \mathrm{ml}(89 \mu \mathrm{M})$, respectively (67). Further studies with a polylactide nanoparticle (PLA) formulation of the compound reduced cutaneous ulcers by $60 \%$ in infected $\mathrm{BALB} / \mathrm{c}$ mice ( $440 \mu \mathrm{g}$ of DMC-PLA x 42 days). The DMCPLA effect was comparable to that of the first-line drug Glucantime ${ }^{\circledR}$ at equivalent doses (68). Nitrosylated DMC, tested intralesionally in mice, was found to be as effective as the first-line drug Pentostam ${ }^{\circledR}$ (69).

Iridoids. Amarogentin [5], a secoiridoid glycoside isolated from Swertia chirata (Gentianaceae), is a potent topoisomerase I inhibitor (Fig. 1). Amarogentin exerts its activity by preventing binary complex formation between DNA and the enzyme (70). In vivo studies have shown strong therapeutic efficacy. The free compound, a liposomal and niosomal formulation (non-ionic surfactant vesicle system), was tested in a hamster model infected with $L$. donovani. The niosomal formulation reduced the splenic parasite load by $90 \%(2.5$ $\mathrm{mg} / \mathrm{kg}$ body weight x 6 days). Toxicity, as studied by blood pathology, histological tissue staining and levels of certain liver enzymes, has not been observed (71). 

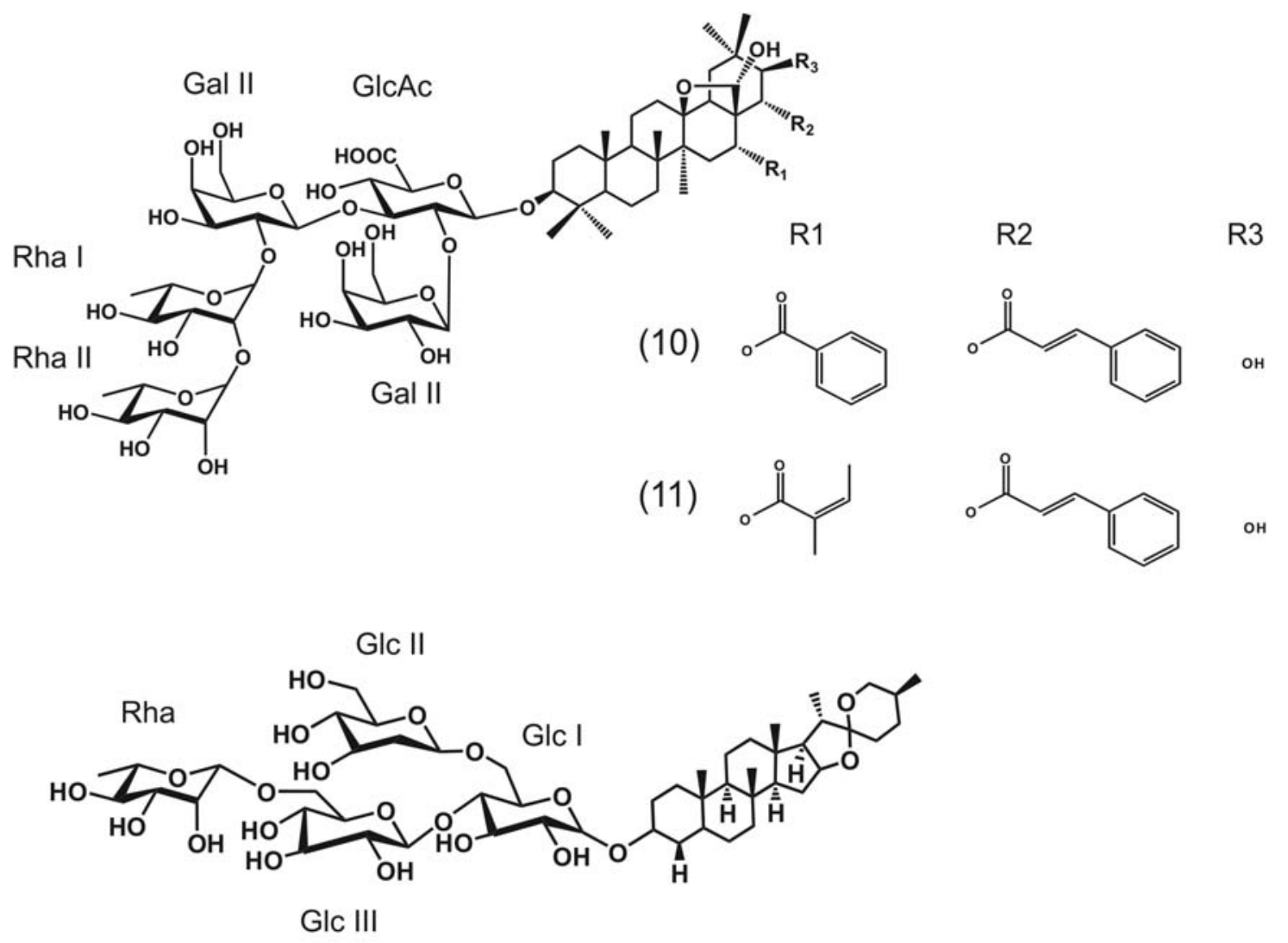

(12)

Figure 2. Chemical structures of maesabalide III [10], maesabalide IV [11] and racemoside A [12].

Naphtoquinones. Plumbagin [6], a naphtoquinone extracted from Pera benensis (Euphorbiaceae) showed inhibitory effects on the growth of $L$. donovani promastigotes and intracellular amastigotes (72) (Fig. 1). $\mathrm{IC}_{50}$ value against promastigotes was $0.21 \mu \mathrm{M}$ (73). Further in vivo studies have shown that plumbagin delayed the development of $L$. amazonensis and L. venezuelensis. Local treatment on a single lesion with 8,8 '-biplumbagin ( $50 \mathrm{mg} / \mathrm{kg}$ body weight) was as potent as the first-line drug Glucantime $\left.{ }^{\circledR}\right)(400 \mathrm{mg} / \mathrm{kg}$ body weight) (74). Plumbagin has been shown to induce topoisomerase II-mediated DNA cleavage (75).

Quinoline alkaloids. 2-Substituted quinolines isolated from Galipea longiflora (Rutaceae) exert strong therapeutic efficacy against experimental CL and VL (Fig. 1). Chimanine B [7] reduced the lesion weight by $74 \%$ and the parasite load by $90 \%$ in L. amazonensis-infected BALB/c mice $(50 \mathrm{mg} / \mathrm{kg}$ body weight $\mathrm{x} 5$ injections at intervals of 4 days) (76). Treatment with chimanine D [8] resulted in $87 \%$ parasite suppression in the liver (100 mg/kg body weight $\mathrm{x} 5$ days $)$. Furthermore, 2-n-propylquinoline [9] reduced liver parasite burden by $99.9 \%$ in an experimental VL model $(94 \mathrm{mg} / \mathrm{kg}$ body weight x 10 days) (77). Recent in vivo studies with various synthetic quinoline derivatives were able to reduce the parasite load by $80-90 \%$ in lesions of L. amazonensisinfected rodents when administered orally at a dose of $25 \mathrm{mg} /$ $\mathrm{kg}$ body weight $\mathrm{x} 10$ days, twice daily. As a reference, the first-line drug Glucantime ${ }^{\circledR}$, administered subcutaneously, reduced the parasite load by $98 \%$ (100 $\mathrm{mg} / \mathrm{kg}$ body weight). In a VL model, the parasite load in the liver was reduced up to $61 \%(12.5 \mathrm{mg} / \mathrm{kg}$ body weight x 10 days). Miltefosine was used as a reference drug and reduced the parasite burdens by $71 \%(7.5 \mathrm{mg} / \mathrm{kg}$ body weight x 10 days) (78).

Saponins. Six oleane triterpenoid saponins mesabalides I-VI derived from Maesa balansae (Myrsinaceae) showed strong anti-leishmanial activity. The most potent components maesabalides III [10] and IV [11] showed an IC $_{50}$ value of 7 and $14 \mathrm{ng} / \mathrm{ml}(5$ and $9 \mathrm{nM}$ ) against L. infantum intracellular amastigotes (79) (Fig. 2). Administration of the purified extract (PX-6518), containing the saponins maesabalides I-VI $(0.4 \mathrm{mg} / \mathrm{kg}$ body weight $\mathrm{x} 1$ day) reduced the parasite burden of the liver by $95 \%$ in a BALB/c mice model one day after infection; $1.6 \mathrm{mg} / \mathrm{kg}$ body weight was needed after two weeks to obtain comparable results (80). However, cytotoxicity was observed at a concentration of $1 \mu \mathrm{g} / \mathrm{ml}$ in macrophage host cells and in MRC-5 cells higher than $32 \mu \mathrm{g} /$ $\mathrm{ml}$. A comparative study showed comparable efficacy of mesabalide III $(0.8 \mathrm{mg} / \mathrm{kg}$ body weight $\mathrm{x} 1$ day $)$ to amphotericin B $(5 \mathrm{mg} / \mathrm{kg}$ body weight $\mathrm{x} 1$ day $)$ in an L. donovaniinfected hamster model (81). Pre-clinical studies of PX-6518 were discontinued due to unacceptable toxicity (32).

A steroidal saponin racemoside A [12] (Fig. 2), isolated from Asparagus racemosus (Liliaceae), induced apoptosis in L. donovani promastigotes and amastigotes. $\mathrm{IC}_{50}$ values were 1.31 and $0.16 \mu \mathrm{g} / \mathrm{ml}$, respectively. Cytotoxicity has not been 
<smiles>[R9]C1CCC2(C)C3CC=C4C5CC(C)(C)CCC5(CC(=O)O)CCC4C(C)(CCC32C)C1(C)C</smiles><smiles>COc1ccc(C(=O)C(C)Sc2ccc(C)cc2)cc1OC</smiles>

(16)

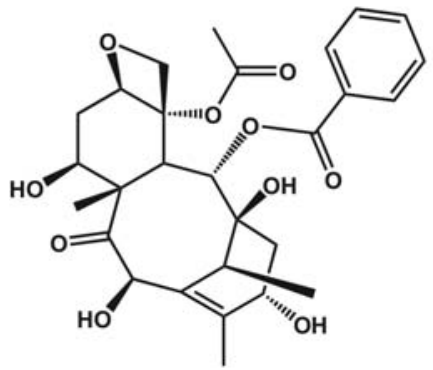

(18)
$\mathrm{R} 1$

(13) Ara 2-1 Rha

(14) Ara 2-1 Rha

(15) Ara[GIc 4-1] 2-1 Rha<smiles>COc1cc2c(O)c3c(c(-c4ccc5c(c4)OCO5)c2cc1OC)C(=O)OC3</smiles>

(17)

\section{R2 \\ $\mathrm{OH}$ \\ $\mathrm{H}$ \\ $\mathrm{H}$}

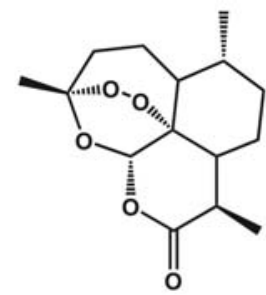

(19)<smiles>C=CC(C)(O)CCC=C(C)C</smiles>

(20)

Figure 3. Chemical structures of $\alpha$-hederin [13], B-hederin [14], hederacolchiside $\mathrm{A}_{1}$ [15], diphyllin [16], 3,4,5-trimethoxy-8-[20,60-dimethoxy-40-(E)propenylphenoxy]-phenylpropane [17], 10-deacetylbaccatin III [18], artemisinin [19] and linalool [20].

observed up to a concentration of $10 \mu \mathrm{g} / \mathrm{ml}$ in murine macrophages (82). Other saponins, namely $\alpha$-hederin [13], B-hederin [14] and hederacolchiside $\mathrm{A}_{1}$ [15] derived from ivy Hedera helix (Araliaceae) exhibited anti-leishmanial properties (Fig. 3). Hederacholchiside $\mathrm{A}_{1}$ appeared to be the most prominent compound with an $\mathrm{IC}_{50}$ value of $1.2 \mu \mathrm{M}$ against $L$. infantum promastigotes and $0.053 \mu \mathrm{M}$ against intracellular amastigotes. Moderate cytotoxicity was observed in human monocytes (83). Moreover it has been shown that $\alpha$-hederin is able to induce nitric oxide production in murine macrophages (84).

Lignans. Diphyllin [16] (Fig. 3) isolated from Haplophyllum bucharicum (Rutaceae) showed anti-leishmanial activity against $L$. infantum promastigotes and intracellular amastigotes. $\mathrm{IC}_{50}$ values were $14.4 \mu \mathrm{g} / \mathrm{ml}(38 \mu \mathrm{M})$ and $0.2 \mu \mathrm{g} /$ $\mathrm{ml}(0.5 \mu \mathrm{M})$, respectively. The lower $\mathrm{IC}_{50}$ value for amastigotes results from inhibition of parasite uptake within macrophages, which is probably due to surface molecule modifications. Diphyllin has been shown to be anti-proliferative against human monocytes $\left[\mathrm{IC}_{50}\right.$ value $\left.35.2 \mu \mathrm{g} / \mathrm{ml}(93 \mu \mathrm{M})\right](85)$. The derivative $\beta$-ketosulfide (3,4-dimethoxy)-8-(40-methyl- thiophenoxy)-propiophenone of the neolignan 3,4,5trimethoxy-8-[20,60-dimethoxy-40-(E)-propenylphenoxy]phenylpropane [17], isolated from Virola pavonis (Myristicaceae) showed moderate activity against L. donovani promastigotes and amastigotes at a concentration of $30 \mu \mathrm{M}$ (Fig. 3). Moreover the compound exhibited in vivo activity, reducing the liver amastigote burden by $42 \%$ at a dose of $100 \mathrm{mg} / \mathrm{kg}$ body weight $\mathrm{x} 5$ days (86).

Taxoids. 10-Deacetylbaccatin III [18], isolated from Taxus baccata (Taxaceae) showed strong anti-leishmanial activity selectively against $L$. donovani intracellular amastigotes (Fig. 3). 10-Deacetylbaccatin III is a precursor molecule of taxol and therefore exhibits chemical similarities. $\mathrm{IC}_{50}$ value was $70 \mathrm{nM}$ for intracellular amastigotes. Moderate growth inhibition of $L$. donovani promastigotes was observed at higher concentrations. 10-Deacetylbaccatin III showed no cytotoxic effects to macrophages up to a concentration of $5 \mu \mathrm{M}$. The activity of 10-deacetylbaccatin is probably due to stimulation of nitric oxide production in macrophages and not by inhibition of microtubule de-polymerization which is the mode of action for paclitaxel in cancer cells (87). 


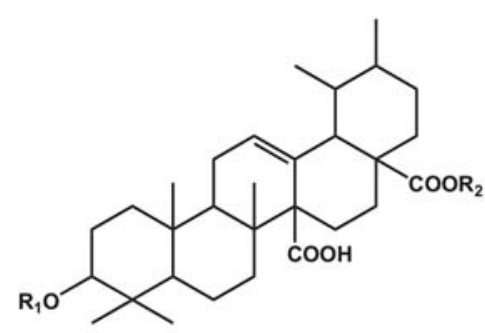

(21-29)<smiles>CCOC1OC=C(C(=O)O)C2CC3c4[nH]c5ccccc5c4CCN3CCC12</smiles>

(30)

\section{R1}

(21)

(22)

(23)

(24)

(25)

(26) beta-D-Glu[1-4]alpha-L-Rham- H

(27) beta-D-Glu-

(28) beta-D-Fuc-

(29) alpha-L-Rham-

(30) beta-D-Glu-

H

\section{R2}

beta-D-Glu-

beta-D-Glu-

beta-D-Glu-

beta-D-Glu-

beta-D-Glu-

H

$\mathrm{H}$<smiles>CCC(C)C(=O)c1c(O)c(CC=C(C)C)c(O)c2c(-c3ccccc3)cc(=O)oc12</smiles>

(33)

(31)

(32)<smiles>C=Cc1ccccc1</smiles>

Figure 4. Chemical structures of quinovic acid glycosides [21-29], cadambine acid [30], coumarin (-) mammea A/BB [31], kavapyrone (+)-(7 R,8 S)-epoxy5,6-didehydrokavain [32] and flavokavain B [33].

Sesquiterpenes. Artemisinin [19], a potent anti-malaria drug, isolated from Artemisia annua (Asteraceae) was recently tested. $\mathrm{IC}_{50}$ values were $160 \mu \mathrm{M}$ against promastigotes and $22 \mu \mathrm{M}$ against intracellular amastigotes (Fig. 3). Macrophage viability was unaffected up to a concentration of $0.25 \mathrm{mM}$. Artemisinin triggers cell cycle arrest in G0/G1 phase and induces apoptosis (88).

Monoterpenes. Linalool [20], a monoterpene extracted from Croton cajucara (Euphorbiaceae), exhibits strong antileishmanial activity against L. amazonensis promastigotes and intracellular amastigotes (Fig. 3). For purified linalool, the $\mathrm{LD}_{50}$ values were $4.3 \mathrm{ng} / \mathrm{ml}(28 \mathrm{nM})$ and $22 \mathrm{ng} / \mathrm{ml}(143 \mathrm{nM})$. Treatment of preinfected murine macrophages with $15 \mathrm{ng} / \mathrm{ml}$ of linalool-rich essential oil reduced the interaction between the macrophages and the parasite by $50 \%$, associated with an increased nitric oxide production. Treatment for $1 \mathrm{~h}$ destroyed $100 \%$ of both promastigotes and intracellular amastigotes, while exhibiting no cytotoxic effect to murine macrophages. In vitro, chromatin plus kinetoplastid destruction and mitochondrial swelling have been observed, followed by cell lysis (89).

Additional natural products. Several quinovic acid glycosides [21-29] isolated from Nauclea diderrichii (Rubiaceae) exert in vitro anti-leishmanial activity against $L$. infantum with $\mathrm{IC}_{50}$ values between 1.1 and $85 \mu \mathrm{M}$ against intracellular amastigotes (Fig. 4). However, all compounds were non-toxic to the Leishmania promastigotes. The alkaloid cadambine acid was also isolated and exhibits an $\mathrm{IC}_{50}$ value of $1.2 \mu \mathrm{M}$ against intracellular amastigotes. Both quinovic acid glycosides and cadambine acid [30] showed weak toxicity towards human macrophages for concentrations higher than $100 \mu \mathrm{M}$. It has been shown that quinovic acid glycosides inhibit parasite internalization and cadambine increases nitric oxide production in macrophages (90).

A coumarin, (-) mammea A/BB [31] was isolated from Calophyllum brasiliense (Clusiaceae). This compound exhibits in vitro leishmanicidal effects on promastigote and amastigote forms of L. amazonensis. $\mathrm{IC}_{50}$ values were $3.0 \mu \mathrm{g} / \mathrm{ml}(7.4 \mu \mathrm{M})$ and $0.88 \mu \mathrm{g} / \mathrm{ml}(2.2 \mu \mathrm{M})$, respectively. (-) Mammea A/BB showed no cytotoxicity in murine macrophages at concentrations mentioned above. Treatment with the compound revealed ultra-structural changes in promastigotes, such as mitochondrial swelling and intense exocytotic activity at the flagellar pocket (91).

Two compounds, namely kavapyrone (+)-(7 R,8 S)epoxy-5,6-didehydrokavain [32] and a chalcone flavokavain B [33], isolated from Piper rusbyi (Piperaceae), showed antileishmanial activity in vitro and in vivo. $\mathrm{IC}_{50}$ values were 81.9 and $11.2 \mu \mathrm{M}$ against L. braziliensis, L. amazonensis, L. donovani promastigotes. In vivo elvaluation in $\mathrm{BALB} / \mathrm{c}$ 
mice infected with L. amazonensis showed that flavokavain B (5 mg/kg body weight x 28 days) reduced lesion size by $32 \%(92)$.

\section{Conclusion}

Leishmaniasis is a poorly investigated disease mainly affecting people in developing countries. Drug screening by the isolation of natural products seems to be an attractive approach which can result in the efficient elucidation of new lead compounds. This is a valuable option to standard screening of large compound libraries. Although a significant number of antileishmanial compounds has been investigated, the number of mechanistic studies is rather small. The actual target sites are unknown in most cases. It is of great importance to probe the active principles of anti-leishmanial agents for subsequent target-based drug design and employment of new screening assays. Furthermore, proteins acting upstream of drug target sites, for instance drug transporters that play a critical role in the development of drugs resistance, must be taken into account. Since the genome sequences of Leishmania major and Leishmania infantum have been elucidated, more sophisticated approaches like microarray-based studies should be developed that offer new possibilities to investigate gene products that play a role in the mode of action of antileishmanial substances and drug resistance. Genomic and proteomic approaches should be used to identify pathways that have already been targeted in other organisms. From a chemical point of view, derivatization of identified lead structures and evaluation of essential binding structures will contribute to improving efficacy and specificity to the parasite. It is important that therapeutic concepts are validated in animal studies. This is not the case for the majority of compounds described in the literature. Therefore, experimental data are not convincing in respect to the selectivity of inhibitory effects. Furthermore, there is a lack of toxicity studies in vivo. We recommend a strong focus on assays using intracellular amastigote cell cultures rather than promastigotes. The amastigote form is the life cycle stage of the parasite relevant to its pathogenicity, and thus data solely obtained from promastigote cell lines are insufficient. This will provide high quality experimental data thus facilitating follow-up studies in vivo.

\section{References}

1. Kedzierski L, Zhu Y and Handman E: Leishmania vaccines: progress and problems. Parasitology 133: S87-S112, 2006.

2. Sukumaran B and Madhubala R: Leishmaniasis: current status of vaccine development. Curr Mol Med 4: 667-679, 2004.

3. Ghosh M and Bandyopadhyay S: Present status of antileishmanial vaccines. Mol Cell Biochem 253: 199-205, 2003.

4. Desjeux P: Worldwide increasing risk factors for leishmaniasis. Med Microbiol Immunol 190: 77-79, 2001.

5. Desjeux P: Leishmaniasis: current situation and new perspectives. Comp Immunol Microbiol Infect Dis 27: 305-318, 2004.

6. Murray HW, Berman JD, Davies CR and Saravia NG: Advances in leishmaniasis. Lancet 366: 1561-1577, 2005.

7. Rosenthal E and Marty P: Recent understanding in the treatment of visceral leishmaniasis. J Postgrad Med 49: 61-68, 2003.

8. Chappuis F, Sundar S, Hailu A, et al: Visceral leishmaniasis: what are the needs for diagnosis, treatment and control? Nat Rev Microbiol 5: 873-882, 2007.

9. Hepburn NC: Cutaneous leishmaniasis: an overview. J Postgrad Med 49: 50-54, 2003.
10. Amato VS, Tuon FF, Bacha HA, Neto VA and Nicodemo AC: Mucosal leishmaniasis. Current scenario and prospects for treatment. Acta Trop 105: 1-9, 2008.

11. Sacks D and Noben-Trauth N: The immunology of susceptibility and resistance to Leishmania major in mice. Nat Rev Immunol 2: 845-858, 2002.

12. Von Stebut E and Udey MC: Requirements for Th1-dependent immunity against infection with Leishmania major. Microbes Infect 6: 1102-1109, 2004.

13. Sundar S, More DK, Singh MK, et al: Failure of pentavalent antimony in visceral leishmaniasis in India: report from the center of the Indian epidemic. Clin Infect Dis 31: 1104-1107, 2000.

14. Gourbal B, Sonuc N, Bhattacharjee H, et al: Drug uptake and modulation of drug resistance in Leishmania by an aquaglyceroporin. J Biol Chem 279: 31010-31017, 2004.

15. Ashutosh, Sundar S and Goyal N: Molecular mechanisms of antimony resistance in Leishmania. J Med Microbiol 56: 143-153, 2007.

16. Zhou Y, Messier N, Ouellette M, Rosen BP and Mukhopadhyay R: Leishmania major LmACR2 is a pentavalent antimony reductase that confers sensitivity to the drug pentostam. J Biol Chem 279: 37445-37451, 2004.

17. Denton H, McGregor JC and Coombs GH: Reduction of antileishmanial pentavalent antimonial drugs by a parasite-specific thiol-dependent reductase, TDR1. Biochem J 381: 405-412, 2004.

18. Yan S, Li F, Ding K and Sun H: Reduction of pentavalent antimony by trypanothione and formation of a binary and ternary complex of antimony(III) and trypanothione. J Biol Inorg Chem 8: 689-697, 2003.

19. Ferreira Cdos S, Martins PS, Demicheli C, Brochu C, Ouellette M and Frezard F: Thiol-induced reduction of antimony(V) into antimony(III): a comparative study with trypanothione, cysteinyl-glycine, cysteine and glutathione. Biometals 16: 441-446, 2003.

20. Wyllie S, Cunningham ML and Fairlamb AH: Dual action of antimonial drugs on thiol redox metabolism in the human pathogen Leishmania donovani. J Biol Chem 279: 39925-39932, 2004

21. Mukherjee A, Padmanabhan PK, Singh S, et al: Role of ABC transporter MRPA, gamma-glutamylcysteine synthetase and ornithine decarboxylase in natural antimony-resistant isolates of Leishmania donovani. J Antimicrob Chemother 59: 204-211, 2007.

22. Decuypere S, Rijal S, Yardley V, et al: Gene expression analysis of the mechanism of natural $\mathrm{Sb}(\mathrm{V})$ resistance in Leishmania donovani isolates from Nepal. Antimicrob Agents Chemother 49: 4616-4621, 2005.

23. El Fadili K, Messier N, Leprohon P, et al: Role of the ABC transporter MRPA (PGPA) in antimony resistance in Leishmania infantum axenic and intracellular amastigotes. Antimicrob Agents Chemother 49: 1988-1993, 2005.

24. Mookerjee Basu J, Mookerjee A, Banerjee R, et al: Inhibition of $\mathrm{ABC}$ transporters abolishes antimony resistance in Leishmania infection. Antimicrob Agents Chemother 52: 1080-1093, 2008.

25. Adler-Moore J and Proffitt RT: AmBisome: liposomal formulation, structure, mechanism of action and pre-clinical experience. J Antimicrob Chemother 49 (Suppl 1): 21-30, 2002.

26. Saha AK, Mukherjee T and Bhaduri A: Mechanism of action of amphotericin B on Leishmania donovani promastigotes. Mol Biochem Parasitol 19: 195-200, 1986.

27. Ramos H, Valdivieso E, Gamargo M, Dagger F and Cohen BE: Amphotericin B kills unicellular leishmanias by forming aqueous pores permeable to small cations and anions. J Membr Biol 152: 65-75, 1996.

28. Mbongo N, Loiseau PM, Billion MA and Robert-Gero M: Mechanism of amphotericin B resistance in Leishmania donovani promastigotes. Antimicrob Agents Chemother 42: 352-357, 1998.

29. Al-Mohammed HI, Chance ML and Bates PA: Production and characterization of stable amphotericin-resistant amastigotes and promastigotes of Leishmania mexicana. Antimicrob Agents Chemother 49: 3274-3280, 2005.

30. Pourshafie M, Morand S, Virion A, Rakotomanga M, Dupuy C and Loiseau PM: Cloning of S-adenosyl-L-methionine:C-24Delta-sterol-methyltransferase (ERG6) from Leishmania donovani and characterization of mRNAs in wild-type and amphotericin B-resistant promastigotes. Antimicrob Agents Chemother 48: 2409-2414, 2004. 
31. Bhattacharya SK, Sinha PK, Sundar S, et al: Phase 4 trial of miltefosine for the treatment of Indian visceral leishmaniasis. J Infect Dis 196: 591-598, 2007.

32. Croft SL and Coombs GH: Leishmaniasis - current chemotherapy and recent advances in the search for novel drugs. Trends Parasitol 19: 502-508, 2003.

33. Perez-Victoria FJ, Sanchez-Canete MP, Seifert K, et al: Mechanisms of experimental resistance of Leishmania to miltefosine: implications for clinical use. Drug Resist Updat 9: 26-39, 2006.

34. Pérez-Victoria FJ, Gamarro F, Ouellette M and Castanys S: Functional cloning of the miltefosine transporter. J Biol Chem 278: 49965-49971, 2003.

35. Perez-Victoria FJ, Sanchez-Canete MP, Castanys S and Gamarro F: Phospholipid translocation and miltefosine potency require both $L$. donovani miltefosine transporter and the new protein LdRos3 in Leishmania parasites. J Biol Chem 281: 23766-23775, 2006.

36. Verma NK and Dey CS: Possible mechanism of miltefosinemediated death of Leishmania donovani. Antimicrob Agents Chemother 48: 3010-3015, 2004.

37. Lux H, Heise N, Klenner T, Hart D and Opperdoes FR: Etherlipid (alkyl-phospholipid) metabolism and the mechanism of action of ether-lipid analogues in Leishmania. Mol Biochem Parasitol 111: 1-14, 2000.

38. Perez-Victoria JM, Perez-Victoria FJ, Parodi-Talice A, et al: Alkyl-lysophospholipid resistance in multidrug-resistant Leishmania tropica and chemosensitization by a novel P-glycoprotein-like transporter modulator. Antimicrob Agents Chemother 45: 2468-2474, 2001.

39. Seifert K, Perez-Victoria FJ, Stettler M, et al: Inactivation of the miltefosine transporter, LdMT, causes miltefosine resistance that is conferred to the amastigote stage of Leishmania donovani and persists in vivo. Int J Antimicrob Agents 30: 229-235, 2007.

40. Castanys-Munoz E, Alder-Baerens N, Pomorski T, Gamarro F and Castanys S: A novel ATP-binding cassette transporter from Leishmania is involved in transport of phosphatidylcholine analogues and resistance to alkyl-phospholipids. Mol Microbiol 64: 1141-1153, 2007.

41. Sundar S: Drug resistance in Indian visceral leishmaniasis. Trop Med Int Health 6: 849-854, 2001.

42. Singh G and Dey CS: Induction of apoptosis-like cell death by pentamidine and doxorubicin through differential inhibition of topoisomerase II in arsenite-resistant L. donovani. Acta Trop 103: 172-185, 2007.

43. Bray PG, Barrett MP, Ward SA and de Koning HP: Pentamidine uptake and resistance in pathogenic protozoa: past, present and future. Trends Parasitol 19: 232-239, 2003.

44. Mehta A and Shaha C: Apoptotic death in Leishmania donovani promastigotes in response to respiratory chain inhibition: complex II inhibition results in increased pentamidine cytotoxicity. J Biol Chem 279: 11798-11813, 2004.

45. Coelho AC, Messier N, Ouellette M and Cotrim PC: Role of the ABC transporter PRP1 (ABCC7) in pentamidine resistance in Leishmania amastigotes. Antimicrob Agents Chemother 51: 3030-3032, 2007

46. Maarouf M, Lawrence F, Croft SL and Robert-Gero M: Ribosomes of Leishmania are a target for the aminoglycosides. Parasitol Res 81: 421-425, 1995.

47. Maarouf M, Lawrence F, Brown S and Robert-Gero M: Biochemical alterations in paromomycin-treated Leishmania donovani promastigotes. Parasitol Res 83: 198-202, 1997.

48. Maarouf M, de Kouchkovsky Y, Brown S, Petit PX and Robert-Gero $\mathrm{M}$ : In vivo interference of paromomycin with mitochondrial activity of Leishmania. Exp Cell Res 232: 339-348, 1997.

49. Maarouf M, Adeline MT, Solignac M, Vautrin D and Robert-Gero M: Development and characterization of paromomycin-resistant Leishmania donovani promastigotes. Parasite 5: 167-173, 1998.

50. Esfandiarpour I and Alavi A: Evaluating the efficacy of allopurinol and meglumine antimoniate (Glucantime) in the treatment of cutaneous leishmaniasis. Int J Dermatol 41: 521-524, 2002.

51. Das VN, Ranjan A, Sinha AN, et al: A randomized clinical trial of low dosage combination of pentamidine and allopurinol in the treatment of antimony unresponsive cases of visceral leishmaniasis. J Assoc Physicians India 49: 609-613, 2001.

52. Yeates C: Sitamaquine (GlaxoSmithKline/Walter Reed Army Institute). Curr Opin Investig Drugs 3: 1446-1452, 2002.
53. Wasunna MK, Rashid JR, Mbui J, et al: A phase II doseincreasing study of sitamaquine for the treatment of visceral leishmaniasis in Kenya. Am J Trop Med Hyg 73: 871-876, 2005.

54. Alrajhi AA, Ibrahim EA, De Vol EB, Khairat M, Faris RM and Maguire JH: Fluconazole for the treatment of cutaneous leishmaniasis caused by Leishmania major. N Engl J Med 346: 891-895, 2002.

55. Sundar S, Singh VP, Agrawal NK, Gibbs DL and Murray HW: Treatment of kala-azar with oral fluconazole. Lancet 348: 614, 1996.

56. Roberts CW, McLeod R, Rice DW, Ginger M, Chance ML and Goad LJ: Fatty acid and sterol metabolism: potential antimicrobial targets in apicomplexan and trypanosomatid parasitic protozoa. Mol Biochem Parasitol 126: 129-142, 2003.

57. Croft SL and Yardley V: Chemotherapy of leishmaniasis. Curr Pharm Des 8: 319-342, 2002.

58. Salem MM and Werbovetz KA: Natural products from plants as drug candidates and lead compounds against leishmaniasis and trypanosomiasis. Curr Med Chem 13: 2571-2598, 2006.

59. Kayser O, Kiderlen AF and Croft SL: Natural products as antiparasitic drugs. Parasitol Res 90 (Suppl 2): 55-62, 2003.

60. Rocha LG, Almeida JR, Macedo RO and Barbosa-Filho JM: A review of natural products with antileishmanial activity. Phytomedicine 12: 514-535, 2005.

61. Mittra B, Saha A, Chowdhury AR, et al: Luteolin, an abundant dietary component is a potent anti-leishmanial agent that acts by inducing topoisomerase II-mediated kinetoplast DNA cleavage leading to apoptosis. Mol Med 6: 527-541, 2000.

62. Das BB, Sen N, Roy A, et al: Differential induction of Leishmania donovani bi-subunit topoisomerase I-DNA cleavage complex by selected flavones and camptothecin: activity of flavones against camptothecin-resistant topoisomerase I. Nucleic Acids Res 34: 1121-1132, 2006.

63. Chen M, Christensen SB, Blom J, et al: Licochalcone A, a novel antiparasitic agent with potent activity against human pathogenic protozoan species of Leishmania. Antimicrob Agents Chemother 37: 2550-2556, 1993.

64. Zhai L, Chen M, Blom J, Theander TG, Christensen SB and Kharazmi A: The antileishmanial activity of novel oxygenated chalcones and their mechanism of action. J Antimicrob Chemother 43: 793-803, 1999.

65. Chen M, Christensen SB, Theander TG and Kharazmi A: Antileishmanial activity of licochalcone A in mice infected with Leishmania major and in hamsters infected with Leishmania donovani. Antimicrob Agents Chemother 38: 1339-1344, 1994.

66. Chen M, Zhai L, Christensen SB, Theander TG and Kharazmi A: Inhibition of fumarate reductase in Leishmania major and $L$. donovani by chalcones. Antimicrob Agents Chemother 45: 2023-2029, 2001.

67. Torres-Santos EC, Moreira DL, Kaplan MA, Meirelles MN and Rossi-Bergmann B: Selective effect of 2',6'-dihydroxy-4'methoxychalcone isolated from Piper aduncum on Leishmania amazonensis. Antimicrob Agents Chemother 43: 1234-1241, 1999.

68. Torres-Santos EC, Rodrigues JM Jr, Moreira DL, Kaplan MA and Rossi-Bergmann B: Improvement of in vitro and in vivo antileishmanial activities of 2', 6'-dihydroxy-4'-methoxychalcone by entrapment in poly(D,L-lactide) nanoparticles. Antimicrob Agents Chemother 43: 1776-1778, 1999.

69. Boeck P, Bandeira Falcao CA, Leal PC, Yunes RA, Filho VC, Torres-Santos EC and Rossi-Bergmann B: Synthesis of chalcone analogues with increased antileishmanial activity. Bioorg Med Chem 14: 1538-1545, 2006.

70. Ray S, Majumder HK, Chakravarty AK, Mukhopadhyay S, Gil RR and Cordell GA: Amarogentin, a naturally occurring secoiridoid glycoside and a newly recognized inhibitor of topoisomerase I from Leishmania donovani. J Nat Prod 59: 27-29, 1996

71. Medda S, Mukhopadhyay S and Basu MK: Evaluation of the invivo activity and toxicity of amarogentin, an antileishmanial agent, in both liposomal and niosomal forms. J Antimicrob Chemother 44: 791-794, 1999.

72. Fournet A, Angelo A, Munoz V, Roblot F, Hocquemiller R and Cave A: Biological and chemical studies of Pera benensis, a Bolivian plant used in folk medicine as a treatment of cutaneous leishmaniasis. J Ethnopharmacol 37: 159-164, 1992.

73. Hazra B, Sarkar R, Bhattacharyya S, Ghosh PK, Chel G and Dinda B: Synthesis of plumbagin derivatives and their inhibitory activities against Ehrlich ascites carcinoma in vivo and Leishmania donovani promastigotes in vitro. Phytother Res 16: 133-137, 2002. 
74. Fournet A, Barrios AA, Munoz V, Hocquemiller R and Cave A: Effect of natural naphthoquinones in BALB/c mice infected with Leishmania amazonensis and L. venezuelensis. Trop Med Parasitol 43: 219-222, 1992.

75. Fujii N, Yamashita Y, Arima Y, Nagashima M and Nakano $\mathrm{H}$ : Induction of topoisomerase II-mediated DNA cleavage by the plant naphthoquinones plumbagin and shikonin. Antimicrob Agents Chemother 36: 2589-2594, 1992.

76. Fournet A, Ferreira ME, Rojas De Arias A, et al: In vivo efficacy of oral and intralesional administration of 2-substituted quinolines in experimental treatment of new world cutaneous leishmaniasis caused by Leishmania amazonensis. Antimicrob Agents Chemother 40: 2447-2451, 1996.

77. Fournet A, Gantier JC, Gautheret A, et al: The activity of 2substituted quinoline alkaloids in BALB/c mice infected with Leishmania donovani. J Antimicrob Chemother 33: 537-544, 1994.

78. Nakayama H, Loiseau PM, Bories C, et al: Efficacy of orally administered 2-substituted quinolines in experimental murine cutaneous and visceral leishmaniases. Antimicrob Agents Chemother 49: 4950-4956, 2005.

79. Germonprez N, Maes L, Van Puyvelde L, Van Tri M, Tuan DA and De Kimpe N: In vitro and in vivo anti-leishmanial activity of triterpenoid saponins isolated from Maesa balansae and some chemical derivatives. J Med Chem 48: 32-37, 2005.

80. Maes L, Vanden Berghe D, Germonprez N, et al: In vitro and in vivo activities of a triterpenoid saponin extract (PX-6518) from the plant Maesa balansae against visceral leishmania species. Antimicrob Agents Chemother 48: 130-136, 2004.

81. Maes L, Germonprez N, Quirijnen L, Van Puyvelde L, Cos P and Vanden Berghe D: Comparative activities of the triterpene saponin maesabalide III and liposomal amphotericin B (AmBisome) against Leishmania donovani in hamsters. Antimicrob Agents Chemother 48: 2056-2060, 2004.

82. Dutta A, Ghoshal A, Mandal D, et al: Racemoside A, an antileishmanial, water-soluble, natural steroidal saponin, induces programmed cell death in Leishmania donovani. J Med Microbiol 56: 1196-1204, 2007.
83. Delmas F, Di Giorgio C, Elias R, et al: Antileishmanial activity of three saponins isolated from ivy, alpha-hederin, beta-hederin and hederacolchiside A1, as compared to their action on mammalian cells cultured in vitro. Planta Med 66: 343-347, 2000.

84. Jeong HG and Choi CY: Expression of inducible nitric oxide synthase by alpha-hederin in macrophages. Planta Med 68: 392-396, 2002

85. Di Giorgio C, Delmas F, Akhmedjanova V, et al: In vitro antileishmanial activity of diphyllin isolated from Haplophyllum bucharicum. Planta Med 71: 366-369, 2005.

86. Barata LE, Santos LS, Ferri PH, Phillipson JD, Paine A and Croft SL: Anti-leishmanial activity of neolignans from Virola species and synthetic analogues. Phytochemistry 55: 589-595, 2000.

87. Georgopoulou K, Smirlis D, Bisti S, Xingi E, Skaltsounis L and Soteriadou K: In vitro activity of 10-deacetylbaccatin III against Leishmania donovani promastigotes and intracellular amastigotes. Planta Med 73: 1081-1088, 2007.

88. Sen R, Bandyopadhyay S, Dutta A, et al: Artemisinin triggers induction of cell-cycle arrest and apoptosis in Leishmania donovani promastigotes. J Med Microbiol 56: 1213-1218, 2007.

89. Do Socorro SRMS, Mendonca-Filho RR, Bizzo HR, et al: Antileishmanial activity of a linalool-rich essential oil from Croton cajucara. Antimicrob Agents Chemother 47: 18951901, 2003.

90. Di Giorgio C, Lamidi M, Delmas F, Balansard G and Ollivier E: Antileishmanial activity of quinovic acid glycosides and cadambine acid isolated from Nauclea diderrichii. Planta Med 72: 1396-1402, 2006.

91. Brenzan MA, Nakamura CV, Prado Dias Filho B, et al: Antileishmanial activity of crude extract and coumarin from Calophyllum brasiliense leaves against Leishmania amazonensis. Parasitol Res 101: 715-722, 2007.

92. Flores N, Cabrera G, Jimenez IA, et al: Leishmanicidal constituents from the leaves of Piper rusbyi. Planta Med 73: 206-211, 2007. 